\title{
VISCOUS FLOW MODEL OF A SUBDUCTION ZONE WITH A FAULTED LITHOSPHERE: LONG AND SHORT WAVELENGTH TOPOGRAPHY, GRAVTTY AND GEOID
}

\author{
Shijie Zhong and Michael Gurnis \\ Department of Geological Sciences, The University of Michigan
}

Abstract. The essential features of observed topography, free air gravity, and the geoid over subduction zones have been reproduced with a dynamically self consistent viscous flow model of a subduction zone with a faulted lithosphere. A fault between the overriding and subducting plates is crucial to understanding lithospheric deformation and gravity in a subduction zone. The topography for models with a fault is characterized by a deep and narrow trench and a broad and shallow back-arc depression, quite different from viscous models without faults which only have a broad and large depression over subducting slabs. For a model in which a slab is $600 \mathrm{~km}$ long and $80 \mathrm{Myr}$ old, the resulting trench is approximately $3 \mathrm{~km}$ deep and $100 \mathrm{~km}$ wide and the back-arc basin is about $1.5 \mathrm{~km}$ deep and $600 \mathrm{~km}$ wide; the model is characterized by a long wavelength geoid high of about $30 \mathrm{~m}$ over the slab, a local geoid low of $10 \mathrm{~m}$ over the trench and a 150 mgal gravity low over the trench. The fact that trench depth and width are reproduced in models with a small resisting shear stress, 50 bars, suggests that convergent plate boundaries are probably weak.

\section{Introduction}

Subduction zones are generally characterized by: 1) $=2$ $5 \mathrm{~km}$ deep and $\approx 150 \mathrm{~km}$ wide trenches; 2) back-arc basins and overriding plates which are topographically depressed by hundreds of meters; 3 ) regional $\left(10^{3}-10^{4} \mathrm{~km}\right.$ wavelength) 10 - 50 meter geoid highs center over slabs; and 4) $\approx 200 \mathrm{mgal}$ free air gravity and ten meter geoid lows over trenches (Figure 1). Large negative free air and geoid anomalies

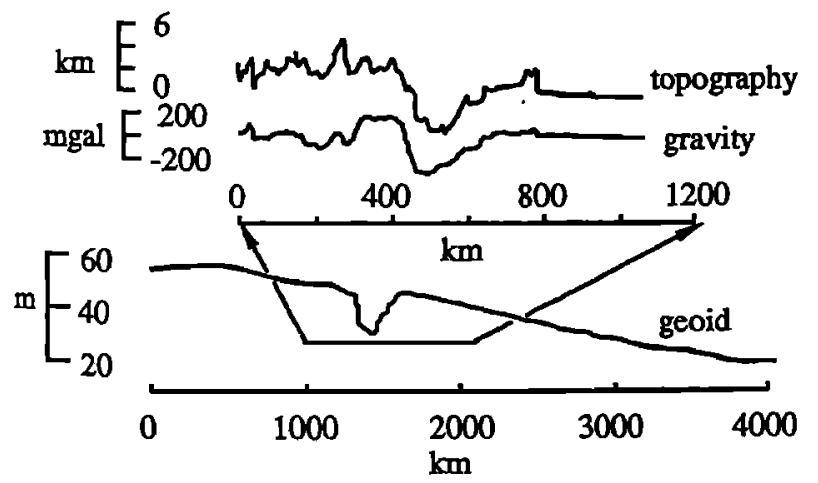

Fig. 1. Observed topography, geoid and free air gravity in the Mariana subduction zone. The topography and free air gravity are from ship tracks [Watts and Talwani; 1974], and the geoid is from Geosat.

Copyright 1992 by the American Geophysical Union.

Paper number $92 \mathrm{GL} 02142$

$0094-8534 / 92 / 92 \mathrm{GL}-02142 \$ 03.00$ suggest that the topography associated with trenches is dynamically supported from depth. The much longer wavelength geoid highs may be driven by the cold and high density slabs within the upper mantle [Chase, 1979; Crough and Jurdy, 1979]. However, Davies [1981] suggested that the mass anomalies associated with long-wavelength geoid highs are smaller than expected from thermal models, and therefore slabs may be regionally compensated, partially, with a broad topographic low. Such geoid highs are suggestive of a lower mantle viscosity which is substantially higher than that of the upper mantle [Hager, 1984]. On a small scale, about $100 \mathrm{~km}$ across, slabs pull the lithosphere down and produce uncompensated trench topography, but on a larger scale slabs are regionally compensated by viscous flow.

In viscoelastic models of a slab isolated from the viscous mantle, positive and negative pressure anomalies are generated beneath the trench and island arc within the subducting plate with prescribed plate velocity [Melosh and Raefsky, 1980]. They suggested that such pressure anomalies caused the trench and island arc topography. Unlike the isolated viscoelastic plate model, viscous flow models have included both slabs and ambient mantle, and have been successfully used to interpret slab dip angles [Hager, et al., 1983] and the time-evolution of subducting plates [Gumis and Hager, 1988]. Such viscous flow models, however, cannot account for the high frequency, but high amplitude trenches. In a model of the Aleutian subduction zone, Sleep [1975] suggested that faults, heterogeneous rheology, and a low density island arc may be necessary to explain subduction zone topography. Nevertheless, Sleep was not successful in explaining the gravity over the island arc, as computed topography which was due primarily to the compensation of a low density island arc had limited effect on free air gravity.

While also realizing the importance of faults, Davies [1981] presented a fractured elastic plate model in which observed subduction zone topography, geoid and gravity could be reproduced. The excess mass of slabs is assumed to be partially compensated, resolving the discrepancy between the anomalous mass predicted from thermal models and that estimated from the observed geoid [Chase, 1979; Crough and Jurdy, 1979]. The compensated anomalous slab mass resulted in a broad back-arc depression and trenches oceanward. However, the compensation mechanism was physically ad hoc, as a functional form of topography was empirically determined in order to reproduce the long wavelength geoid.

Here we present a new formulation of viscous flow with faults which is essential to an understanding of lithospheric and mantle deformation and terrestrial gravity. When a fault cuts through a high viscosity lithosphere with a cold slab driving the flow, we find that the computed dynamic topography is characterized by a narrow trench and a broad back-arc basin. The computed dynamic topography allows us 
to simultaneously explain the geoid, gravity, and topography observations on both a short and a long wavelength. Furthermore, the long-wavelength back-arc depression compared with models without a fault is reduced significantly, but we still find that long wavelength geoid highs require a high viscosity lower mantle.

\section{Method}

We have developed a two dimensional viscous flow model of a subduction zone with a fault. To model a fault fully even in two dimensions is difficult, and proper simplifications based on our current understanding of faults are necessary. A clearly defined seismic fault plane separates the subducting plate from the overriding plate and the plate subducts into the mantle along the fault plane. Faults like the San Andreas may be too weak to maintain large shear stresses [Kanamori, 1980], as supported by studies of large earthquakes [Kanamori, 1980], heat flow [Lachenbruch and Sass, 1988] and in situ stress measurements [Zoback and Healy, 1992]. Only laboratory studies of rock deformation suggest that faults may be strong [Byerlee, 1978]. Furthermore, material on the two sides of faults must slide along the fault plane and cannot cross the fault.

In our new Eulerian model, the fault plane is represented as an interface and has the following constraints: a) the interface is fixed and prescribed; b) the interface either decouples (with zero shear stress) or weakly couples (with a small shear stress) the flow from one side to the other; and c) the flow on the interface is parallel to the interface.

For flow in the Earth's mantle, where inertial forces are negligible, the momentum and continuity equations, using the Boussinesq approximation, become

$$
\mu \nabla^{2} u=-\nabla p+p_{o} \alpha\left(T-T_{0}\right) g k,
$$

and

$$
\nabla \cdot \mathbf{u}=0,
$$

where $T$ is temperature, $p$ is pressure, $\rho_{0}$ and $T_{0}$ are reference density and temperature, respectively, $\mu$ is dynamic viscosity, $g$ is gravitational acceleration, $\alpha$ is coefficient of thermal expansion, and $\mathbf{k}$ is the unit vector in the vertical direction positive downward. The equations are solved with a finite element method in which a penalty formulation, using selective and reduced integration, enforces incompressibility [Hughes, 1987; King et al., 1990].

The fault-like interface in our model is treated as a fixed boundary. In order to incorporate the fault, special finite element techniques are employed. Those nodes having the same coordinates, but on different side of the interface have different degrees of freedom (dof), as done in interface problems in engineering [Cook, 1981]. With such dof's the flow can be decoupled or weakly coupled on either side of the interface, depending on the prescribed shear stress on the interface. By using constrained element and matrix transformation techniques [Cook, 1981], the flow on the interface is parallel to the interface.

The fault-like interface has been incorporated into a model of a subduction zone (Figure 2). The fault plane is assumed to extend down to the base of a high viscosity lithosphere. Dip angles of subduction, $\theta_{\mathrm{f}}$, within the

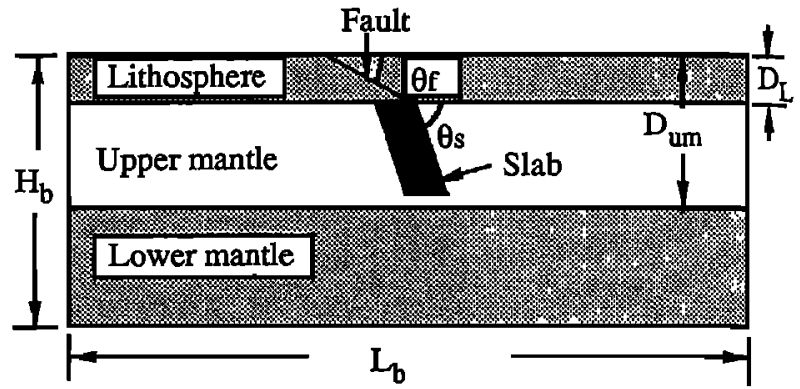

Fig. 2. A viscous flow model of subduction zones with a fault. $\mathrm{H}_{b}=3000 \mathrm{~km} ; \mathrm{L}_{b}=9000 \mathrm{~km} ; \mathrm{D}_{\mathrm{L}}=100 \mathrm{~km} ; \mathrm{D}_{\mathrm{um}}=700$ $\mathrm{km}$; the dip angle, the age, the length and the thickness of the slab are $60^{\circ}, 80 \mathrm{Myr}, 600 \mathrm{~km}$ and $100 \mathrm{~km}$, respectively, for all the models shown; the viscosity of lower mantle equals that of lithosphere and is 100 times of upper mantle viscosity which equals $10^{20}$ poise. Coefficient of thermal expansion, $\alpha$, gravitational acceleration, $g$, density of the mantle, $p_{0}$, and reference temperature, $T_{0}$, are $2.0 \times 10^{-5} \mathrm{~K}^{-1}, 10 \mathrm{~ms}^{-2}, 3.3 \times 10^{3}$ $\mathrm{kgm}^{-3}$ and $1500 \mathrm{~K}$, respectively.

lithosphere are usually much smaller than those of slabs, $\theta_{s}$ [Jarrard, 1986]. Since trench depth strongly correlates with the $\theta_{\mathrm{f}}$ but not with the $\theta_{\mathrm{s}}$ [Jarrard, 1986], we independently varied these two dip angles. The negative buoyancy within the slab is equated to the buoyancy within the oceanic plate from its subsidence just prior to subduction and is uniformly distributed through the whole slab. The boundary conditions on the four sides are free slip.

Sufficient elements (200 and 74 elements in horizontal and vertical directions, respectively) are used to resolve the flow near the trench and slab. The horizontal spacing of elements in the vicinity of the fault is $15 \mathrm{~km}$; at least eight elements are used to resolve trenches. To assure accuracy, only quadrilateral elements are used. We have developed a new approach to computing normal stresses on the surface such that dynamic topography can be accurately determined [Zhong, et al., submitted]. The geoid and gravity which include both internal and topographic contributions are computed using a spectral method.

\section{Results and Discussions}

Models with a wide range of parameters consistently show dynamic topography which is characterized by a narrow and deep trench and a broad back-arc basin. Such dynamic topography allows us to explain observed long and short wavelengths geoid and free air anomalies over subduction zones. In order to demonstrate the basic physics of faults and their effects on gravity and topography, we only discuss a few cases and compare them with cases without faults.

Dynamic topography, with a water load, for models with a fault dip, $\theta_{\mathfrak{f}}$, of $30^{\circ}$ and a slab dip, $\theta_{\mathrm{s}}$, of $60^{\circ}$, a length of $600 \mathrm{~km}$, and an age of $80 \mathrm{Myr}$ clearly show a trench and depressed back-arc basin when the fault has zero or small shear stress (Figure 3a). As expected, as the shear stress on the fault increases, depression of the tip of overriding plates increases and the depth of the trench decreases. For a case WF with 50 bar shear stress, the trench is about $100 \mathrm{~km}$ wide and $3.5 \mathrm{~km}$ deep, and the back-arc basin is about $600 \mathrm{~km}$ 

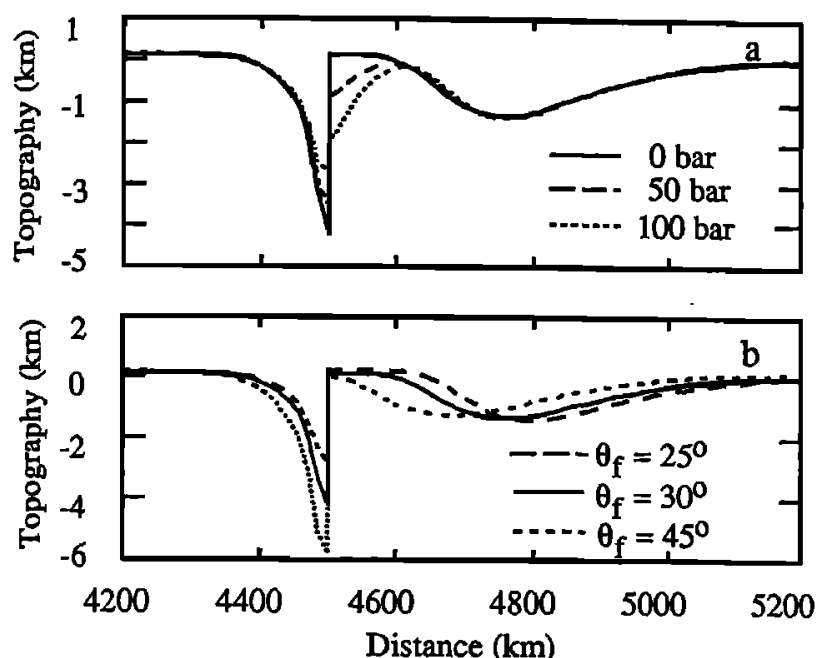

Fig. 3. Dynamic topography for a) models with different resistent shear stress on the fault, and b) models with different fault dip angles. All the topographies are computed with a water load but without an elastic lid. Other parameters are the same as those in Figure 2.

wide and $1.5 \mathrm{~km}$ deep (Figure 3a). This is the first time that the essential features of trenches have been reproduced with the actual forces, buoyancy forces, incorporated in a dynamically self-consistent manner.

Elasticity of the lithosphere has little effect on the dynamic topography whose wavelength of about $100 \mathrm{~km}$ is much longer than the flexural length of the lithosphere. Loading the dynamic topography from WF on a thin elastic plate with a end free only makes the trench shallower by about $0.6 \mathrm{~km}$ (Figure 4a). The dynamic topography for an identical model NF but with no fault, is characterized by a broad depression over the slab (Figure 4a), as has long been known in viscous models of slabs [cf. Hager, 1984]. The maximum depression of $2.5 \mathrm{~km}$ occurs far "landward" behind the trench and such dynamic topography is fundamentally different from observed topography.

The difference in dynamic topography between the models WF and NF is due to the effects of the fault on the broad viscous flow. In both cases slabs viscously pull the lithosphere downward. Without a fault, there is a broad distributed depression with its maximum nearly above the slab center of mass. However, when a weak fault interface is present between the subducting and the overriding plates, the viscous force of the slab acting on the surface is redistributed and the force on the subducting plate becomes much more concentrated and results in a larger amplitude, but narrow depression oceanward of the fault. The force on the overriding plate is reduced and nearly vanishes directly above the interface, causing a back-arc basin with a smaller amplitude. Clearly, a weak fault is essential in determining the stress field and surface topography of subduction zones.

The dynamic topography of the model WF allows us to simultaneously reproduce observed free air gravity and short and long wavelength geoid. The computed geoid is characterized by a long wavelength geoid high of about $30 \mathrm{~m}$ over the slab and a short wavelength low of $10 \mathrm{~m}$ over the trench (Figure $4 \mathrm{~b}$ ). The computed free air gravity has $\approx 150$ mgal low over the trench and $\approx 80 \mathrm{mgal}$ high over the observed position of an island arc (Figure 4c). The computed geoid and free air gravity for the model WF are remarkably similar to the general trend of observations over subduction zones (Figure 1), but this is not the case for a model without a fault (Figures $4 \mathrm{~b}$ and $4 \mathrm{c}$ ).

In order to obtain the long wavelength geoid highs, the viscosity of the lower mantle must be higher than that of the upper mantle (a factor of 100 in all the cases shown), as originally shown by Hager [1984]. The long wavelength geoid of WF is much higher than that of NF, and this can be explained with the topography spectra of these two models. Compared with NF, the magnitude of short wavelength topography of WF ( $200 \mathrm{~km}$ wavelength) increases significantly, reflecting the deep and narrow trench, while the magnitude of long wavelength topography $(\sim 3000-9000 \mathrm{~km}$ wavelength) of WF is reduced by about $30 \%$, reflecting the shallower back-arc basin. Since the geoid is strongly attenuated for short wavelength, the deep trench of the model WF only lowers the geoid by a few meters near the trench, but the smaller effective compensation of a shallower basin increases the long wavelength geoid high.

The computed free air gravity mainly reflects the shorter wavelength dynamic topography of the trench and the "arc". While the trench depth and the free air gravity low over the trench are almost identical to observed values, elevation of the "arc" and gravity high over the "arc" are smaller than observed. This is probably because island arcs, unlike trenches, are not completely compensated and part of the free air high over island arc is from the uncompensated nondynamic topography. Another possible reason is that our models exclude a low density island arc. As shown by Sleep [1975], a low density island arc would produce a topography and gravity highs over the arc, although it alone cannot explain the observed gravity high.
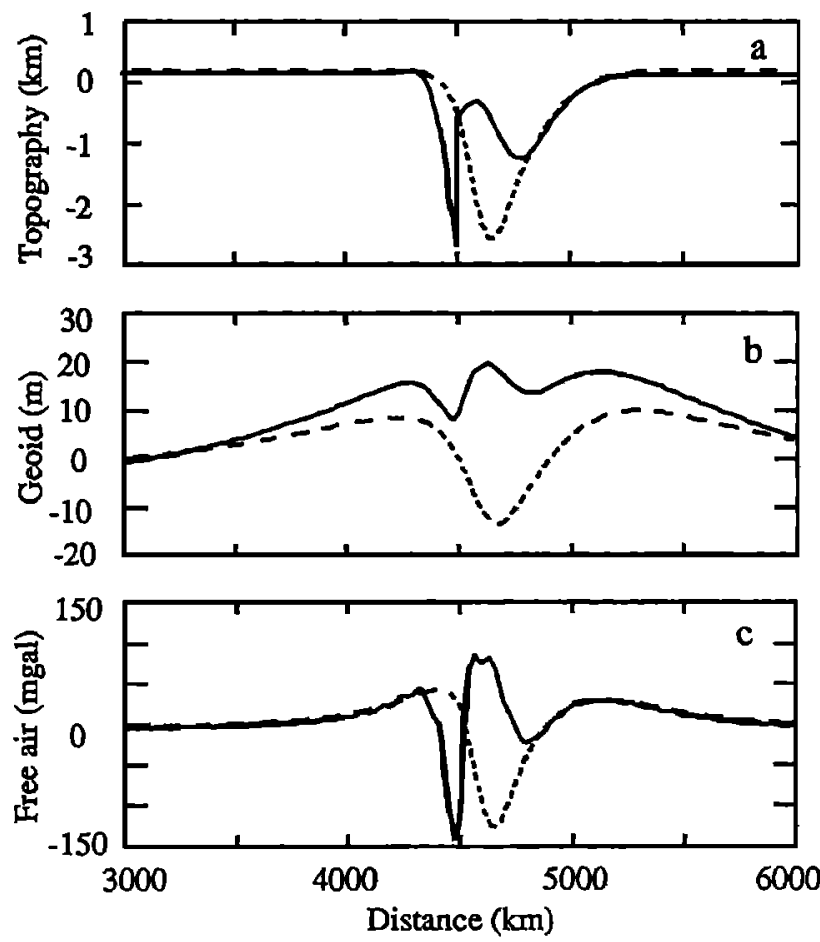

Fig. 4. Computed dynamic topography (a), geoid (b), and free air gravity (c) for the models WF (solid line) and NF (dash line). The lithosphere in the WF case loads a thin elastic plate with a rigidity of $10^{23} \mathrm{~N}-\mathrm{m}$. 
Dynamic topography is controlled by the age of slabs, the dip angles of slabs and faults, and the length of slabs. As expected, the longer a slab or the older a slab, i.e. the greater the mass anomaly, the deeper the trench and the back-arc basin. Since the momentum equation (eq. 1) is linear with the linear viscous rheology, the amplitude of trench depth is directly proportional to the temperature difference between the slab and its surroundings, and hence to the square root of lithospheric age just prior to subduction. Our computations show that the dip angle of faults is a critical parameter determining topography. The larger the dip angle of the fault, the deeper the trench (Figure $3 \mathrm{~b}$ ). These results are consistent with the observed trench depths from all the subduction zones [Hilde and Uyeda, 1983; Jarrard, 1986]. The ratio of lithosphere viscosity to upper mantle viscosity is also significant and must be large enough (100 for all the cases shown) in order to obtain a deep and narrow trench.

Because we can easily reproduce observed topography, geoid and free air in subduction zones with a small resisting shear stress on the fault, this implies that convergent plate boundaries are weak. The resisting shear stresses of 50 and 100 bars in our models are close to values suggested from seismic studies of large tectonic faults [Kanamori, 1980].

\section{Conclusions}

By incorporating a weak fault into models of viscous flow, we can reproduce the topography of trenches and backarc basins, the free air gravity, and the long and short wavelength geoid signals which are observed in subduction zones. For a model with typical subduction zone parameters, the computed trench is about $100 \mathrm{~km}$ wide and $3 \mathrm{~km}$ deep, and the back-arc basin is about $600 \mathrm{~km}$ wide and $1.5 \mathrm{~km}$ deep. The computed geoid is characterized by $a=30 \mathrm{~m}$ long wavelength high over the slab. The free air is $\approx-150 \mathrm{mgal}$ over the trench and $\approx+80 \mathrm{mgal}$ over the arc. These results are very close to the general observations of subduction zones. The fault with a small resisting shear stress is essential to producing trenches and back-arc basins. Of many parameters controlling the topography, the dip angle of fault and the age of slab are most significant, consistent with observed trends.

Acknowledgment. We thank Xiaohong Wang for help in designing elements for cases with small dip angles. $H$. Pollack made helpful comments on the manuscript. Funded by the David and Lucile Packard Foundation and NSF grants EAR-8957164 and EAR-8904660.

\section{References}

Byerlee, J. D., Friction of rocks, Pure Appl. Geophys., 116, 615-626, 1978.

Chase, C. G., Subduction, the geoid, and lower mantle convection, Nature, 282, 464-468, 1979.

Cook, R. D., Concepts And Application of Finite Element
Analysis, Second Edition, 537 pp., John Wiley \& Sons Inc., New York, 1981.

Crough, S. T. and Jurdy, D. M., Subducted lithosphere, hot spots, and the geoid, Earth Planet. Sci. Lett., 48, 15-22, 1980.

Davies, G. F., Regional compensation of subducted lithosphere: Effects on geoid, gravity and topography from a preliminary model, Earth Planet. Sci. Lett, 54 431-441, 1981.

Gurnis, M. and Hager, B. H., 1988, Controls on the structure of subducted slabs, Nature, 335, 317-322, 1988.

Hager, B. H., Subducted slabs and the geoid: constrains on mantle rheology and flow, J. Geophys. Res. 89, 6003. $6015,1984$.

Hager, B. H., O'Connell, R. J., and Raefsky, A., Subduction, back-arc spreading and global mantle flow, Tectonophysics, 29, 165-189, 1983.

Hilde, T. W. C. and Uyeda, S., Trench depth: Variation and significance, in Geodynamics of the Western PacificIndonesian Region. Geodyn. Ser, vol. 11, edited by $T$. W. C. Hilde and S. Uyeda, pp. 75-89, AGU, Washington, D. C., 1983.

Hughes, T. J. R., The Finite Element Method, 631pp., Prentice-Hall, Englewood Cliffs, N.J., 1987.

Jarrard, R. D., Relations among subduction parameters, Rev. Geophys., 24, 217-284, 1986.

Kanamori, $H$., The state of stress in the Earth's lithosphere, Pure Appl. Geophys., 118, 1980.

King, S. D., Raefsky, A. and Hager, B. H., ConMan: Vectorizing a finite element code for incompressible two-dimensional convection in the Earth's mantle, Phys. Earth Planet. Inter, 59, 195-207, 1990.

Lachenbruch, A. H. and Sass, J. H., The stress heat-flow paradox and thermal results from Cajon Pass, Geophys. Res. Lett., 15, 981-984, 1988.

Melosh, H. J. and Raefsky, A., The dynamical origin of subduction zone topography, Geophys. J. R astr. Soc. 60, 333-354, 1980.

Sleep, N. H., Stress and flow beneath island arcs, Geophys. I. R, astr. Soc., 42, 827-857, 1975.

Watts, A. B., and Talwani, M., Gravity anomalies seaward of deep-sea trenches and their tectonic implications, Geophys. J. R. astr. Soc., 36, 57-90, 1974.

Zoback, M. D. and Healy, J. H., In-situ stress measurements to $3.5 \mathrm{~km}$ depth in the Cajon Pass scientific research bore hole: Implications for the mechanism of crustal faulting. L. Geophys. Res., 27, 5039-5057, 1992.

M. Gurnis and S. Zhong, Department of Geological Sciences, The University of Michigan, Ann Arbor, MI 48109-1063.

(Received: June 22, 1992; accepted August 17, 1992.) 